Revista Científica ANAP Brasil

ISSN 1984-3240 - Volume 14, número 32, 2020

\title{
A Utilização do Geoprocessamento como Ferramenta de Gestão no Processo de Modernização da lluminação Pública na Cidade do Recife-PE
}

Geoprocessing Use as a Management Tool in the Public Lighting Process Modernization at the City of Recife-PE

El uso del geoprocesamiento como herramienta de gestión en el proceso de modernización del alumbrado público en la ciudad de Recife-PE

Lúcio Luiz Fidélis de Freitas Júnior Diretor Executivo de lluminação Pública-EMLURB Ifidelis@recife.pe.gov.br

Marília Dantas da Silva Diretora Presidente- EMLURB mariliad@recife.pe.gov.br

Micaella Raíssa Falcão de Moura Professora Dra. Estácio do Recife micaellaraissa@hotmail.com 


\title{
Revista Científica ANAP Brasil
}

\author{
ISSN 1984-3240 - Volume 14, número 32, 2020
}

\section{RESUMO}

O trabalho tem como objetivo mostrar as principais características e vantagens apresentadas mediante a otimização do gerenciamento do setor de lluminação Pública (IP) da cidade do Recife-PE, especialmente considerando a aquisição de dados técnicos e uso das geotecnologias como ferramenta estratégica da IP. Para tal, melhorias foram implantadas no setor responsável pela gestão da iluminação pública da cidade, sendo realizadas as seguintes etapas: i) Identificação das necessidades físicas e operacionais, para devida reestruturação; ii) Gestão estratégica, considerando a elaboração dos projetos, especificação e qualidade de materiais e fiscalização das obras; iii) Definição de indicadores para monitoramento dos serviços e controles contratuais; e iv) Análise dos indicadores dos ativos de iluminação pública. A metodologia utilizou ainda o projeto llumina Recife, promovido pela prefeitura da cidade do Recife, o qual realizou a instalação de 5.045 novos pontos luminosos de iluminação pública em LED nos grandes corredores, periferias, praças e parques da cidade. Como principais resultados, têm-se que o geoprocessamento das informações obtidas a partir da aquisição de dados técnicos atualizados do sistema de iluminação pública permite ao gestor público que as manutenções corretivas a serem realizadas pelas equipes técnicas sejam mais eficientes, melhorando a qualidade e garantindo a continuidade do serviço prestado à população.

PALAVRAS-CHAVE: Iluminação pública. Gestão pública. Geoprocessamento.

\begin{abstract}
The work aims to show the main characteristics and advantages presented by optimizing the Public Lighting (IP) management sector in the city of Recife-PE, especially considering the acquisition of technical data and the use of geotechnologies as a strategic tool of IP. To this end, improvements were implemented in the sector responsible for the management of public lighting in the city, with the following steps being taken: i) Identification of physical and operational needs, for due restructuring; ii) Strategic management, considering the elaboration of projects, specification and quality of materials and inspection of works; iii) Definition of indicators for monitoring services and contractual controls; and iv) Analysis of the indicators of public lighting assets. The methodology also used the project Ilumina Recife, promoted by Recife's City hall, which installed 5,045 new luminous points of public LED lighting in the city's great corridors, peripheries, squares, and parks. As main results, the geoprocessing of the information obtained from the acquisition of updated technical data from the public lighting system allows the corrective maintenance to be carried with more efficiency by the technical teams, improving the quality and ensuring the continuity of the service provided to the population.
\end{abstract}

KEYWORDS: Public lighting. Public Management. Geoprocessing.

\section{RESUMEN}

El trabajo tiene como objetivo mostrar las principales características y ventajas presentadas al optimizar la gestión del sector de alumbrado público (IP) en la ciudad de Recife-PE, especialmente considerando la adquisición de datos técnicos y el uso de geotecnologías como una herramienta estratégica de IP. Con este fin, se implementaron mejoras en el sector responsable de la gestión del alumbrado público en la ciudad, con los siguientes pasos: i) Identificación de las necesidades físicas y operativas, para la debida reestructuración; ii) Gestión estratégica, considerando la elaboración de proyectos, especificación y calidad de materiales e inspección de obras; iii) Definición de indicadores para el monitoreo de servicios y controles contractuales; y iv) Análisis de los indicadores de activos de alumbrado público. La metodología también utilizó el proyecto llumina Recife, promovido por la ciudad de Recife, que instaló 5.045 nuevos puntos luminosos de iluminación LED pública en los grandes corredores, periferias, plazas y parques de la ciudad. Como resultados principales, el geoprocesamiento de la información obtenida de la adquisición de datos técnicos actualizados del sistema de alumbrado público permite al gerente público que el mantenimiento correctivo a ser realizado por los equipos técnicos sea más eficiente, mejorando la calidad y garantizando la continuidad del servicio prestado a la población.

PALABRAS CLAVE: Alumbrado público. Gestión pública. Geoprocesamiento. 


\title{
Revista Científica ANAP Brasil
}

\author{
ISSN 1984-3240 - Volume 14, número 32, 2020
}

\section{INTRODUÇÃO}

O serviço público é uma atividade desenvolvida com a participação direta do estado e garantida pela Constituição Federal de 1988 (BRASIL, 1988). No que se refere aos serviços de Iluminação Pública (IP), os projetos são elaborados para as mais diversas finalidades, mas, em geral, têm-se entre os principais objetivos: garantir o tráfego de pessoas, veículos e outros meios de transportes em ruas e avenidas; assegurar o uso dos espaços públicos pela população, principalmente no período noturno, trazendo mais conforto e segurança; ressaltar áreas de destaque na Cidade; contribuir para o desenvolvimento social e econômico da população, além de reduzir o consumo de energia, prezando pelas questões ambientais (ALMEIDA; PASSINI, 2002; MOREIRA, 1999).

Nesse sentido, a gestão visa melhorar a qualidade dos serviços de lluminação Pública, desenvolvendo e aperfeiçoando práticas de manutenção, incluindo soluções de remodelação e ampliação da Rede de IP da cidade, bem como a análise do fornecimento de materiais de acordo com as especificações e critérios estabelecidos em normas. Garantir a provisão destes serviços de forma contínua, eficiente, acessível a toda a sociedade e utilizando técnicas modernas tem sido um dos principais desafios enfrentados pelos gestores (COSTA, 2001; MARTINS, 2011).

Considerando-se a importância da temática, este trabalho foi desenvolvido após a conclusão de melhorias implantadas pela gestão municipal no setor responsável pela iluminação pública da cidade do Recife, Pernambuco-Brasil entre os anos de 2017 e 2019. Dessa forma, o objetivo deste artigo é mostrar as principais características e vantagens apresentadas mediante a otimização do gerenciamento do setor, especialmente considerando a aquisição de dados técnicos e uso das geotecnologias como ferramenta estratégica da IP.

O estudo foi direcionado em quatro eixos: I) o conhecimento acerca da iluminação pública e a transferência deste ativo para a gestão municipal das cidades; II) o geoprocessamento e as principais geotecnologias; III) a aquisição dos dados técnicos do sistema de iluminação e IV) a necessidade de utilizar os bancos de dados obtidos para a gestão estratégica da IP. O trabalho busca estabelecer as condições de gerenciamento dos serviços, compatibilizando os recursos financeiros, humanos, materiais e equipamentos disponíveis para a gestão de manutenção de iluminação pública do Recife, de forma a apresentar o planejamento realizado para alcançar resultados mais efetivos no que se refere a custo e qualidade.

\section{CARACTERIZAÇÃO DA ÁREA DE ESTUDO}

A área de estudo está localizada na cidade do Recife, no Estado de Pernambuco, Brasil, sendo considerada na hierarquia urbana nacional uma Metrópole Regional. Com área territorial de 218,75 km², a capital de Pernambuco é dividida em seis Regiões Político Administrativas (RPAs), constituídas por 94 bairros, sendo o Sistema de lluminação Pública composto por 97.857 Unidades de lluminação, atualmente, o nono maior parque de lluminação Pública do País.

A carga instalada da rede de IP atinge cerca de 11,69 MW e, em condições normais, o consumo médio mensal de energia é da ordem de $4,88 \mathrm{GW} / \mathrm{mês}$. Atualmente a demanda para manutenção das instalações do parque instalado é cerca de $80 \%$ maior que as demandas para a expansão das Unidades de lluminação. A alimentação do Sistema é realizada por transformadores ou 


\title{
Revista Científica ANAP Brasil
}

\author{
ISSN 1984-3240 - Volume 14, número 32, 2020
}

a partir da rede secundária da Concessionária, onde basicamente os circuitos são aéreos. A Prefeitura tem se dedicado sobre o tema do embutimento da fiação, realizando estudos técnicos para este fim. A Tabela 1 Identifica, respectivamente, o tipo e a quantidade de lâmpadas existentes no Recife.

Tabela 1-Informações acerca do sistema de iluminação pública da cidade do Recife.

\begin{tabular}{l|l}
\hline \multicolumn{1}{c|}{ TIPO } & \multicolumn{1}{c}{ QUANTIDADE } \\
\hline Vapor de sódio (VS) & 84.874 \\
\hline Vapor metálico (VM) & 5.074 \\
\hline Light-emitting diode (LED) & 7.909 \\
\hline TOTAL & $\mathbf{9 7 . 8 5 7}$ \\
\hline Carga instalada da rede & $\mathbf{1 1 , 6 9 ~ \mathbf { ~ W }}$ \\
\hline Consumo médio & $\mathbf{4 , 8 8 ~} \mathbf{~ W / m e ̂ s}$ \\
\hline
\end{tabular}

Fonte: AUTORES, 2019

O processo de modernização do sistema de iluminação pública na cidade do Recife está diretamente relacionado a algumas importantes ações ligadas à gestão pública e a respectiva capacidade operativa do Município. Algumas necessidades físicas e operacionais foram identificadas na estrutura da Gestão Municipal para que o processo de modernização acontecesse, conforme relação abaixo:

a) Investimentos na modernização do parque, mudança na perspectiva de manutenção através da alteração de características como altura das luminárias;

b) Contratação do cadastro de iluminação, testes de implementação de equipamentos que possibilitem uma melhor avaliação do sistema;

c) Implantação do software de gerenciamento;

d) Melhora no atendimento ao munícipe- 156 CCO;

\section{METODOLOGIA: GEOPROCESSAMENTO DO CADASTRO DE ILUMINAÇÃO PÚBLICA}

\subsection{Aquisição dos dados técnicos do sistema de iluminação pública}

As áreas de administração municipal podem encontrar no geoprocessamento e nas geotecnologias importantes aliados nas etapas de levantamento de dados, diagnósticos de problemas, tomadas de decisões, planejamento estratégico, projetos, execução de ações e medições dos resultados. De maneira geral, o fato de poder conhecer onde os problemas ocorrem e poder visualizá-los espacialmente facilita o seu entendimento e antecipa possíveis soluções aos gestores públicos. $O$ estágio atual das geotecnologias permite fazer uma análise espacial que combine 0 mapeamento dos problemas urbanos com informações físicas, demográficas, geográficas, topográficas ou de infraestrutura. Esta análise levará a adoção de uma solução mais racional em menor tempo.

Segundo Borges (2000), a manipulação integrada de dados gráficos e não gráficos, juntamente com a possibilidade de análises espaciais, pode orientar as tomadas de decisão e o planejamento, além de auxiliar na avaliação da eficácia das políticas públicas de intervenção. Do 


\title{
Revista Científica ANAP Brasil
}

\author{
ISSN 1984-3240 - Volume 14, número 32, 2020
}

ponto de vista de iluminação pública, o cadastramento georreferenciado dos ativos consiste no serviço realizado dentro do perímetro do município, cujo objetivo principal é a coleta dos dados técnicos dos equipamentos que compõem o sistema municipal de IP e dos componentes, equipamentos e estruturas pertencentes à distribuidora de energia elétrica local.

A realização do cadastro georreferenciado dos componentes do sistema visa instrumentalizar a gestão dos serviços de iluminação pública, assim considerado como base para controle de manutenção e projetos de melhoramentos e expansão. Visa ainda otimizar a fiscalização do faturamento da energia elétrica consumida mensalmente junto à concessionária local de distribuição de energia elétrica. Para a realização do cadastramento informatizado de todos os pontos de IP pertencentes ao município, se faz necessária a utilização de geoprocessamento e demais geotecnologias (SANTANA, 2009; XAVIER-DA-SILVA, 2001).

$O$ cadastramento georreferenciado é de extrema relevância tendo em vista a necessidade de se obter a localização precisa para cada ponto de IP instalado em ruas, avenidas, viadutos, travessas, parques, praças e outros logradouros. Portanto, tal cadastramento contribui para dimensionar o valor das despesas com energia elétrica, subsidiar contratações mais eficientes quanto à manutenção corretiva e preventiva de todo o sistema e servir como ponto de partida para a definição de novos projetos de remodelação que gerem benefícios para a administração pública e principalmente para a população.

Para fins de obtenção de dados técnicos coerentes e que sirvam para a base de diretrizes estratégicas da iluminação pública, toda a área do município deve ser percorrida pelos profissionais designados pela gestão municipal ou por empresa contratada através de licitação para execução de tais serviços. Para tal, deve-se respeitar os limites estabelecidos pelo Instituto Brasileiro de Geografia e Estatística (IBGE) ou Sistemas de Informações Geográficas (SIG) municipal, coletando as mais diversas informações associadas aos pontos luminosos, tais como:

- Nome do Logradouro (ruas, avenidas, travessas, escadarias, praças, parques, campos, jardins municipais, túneis, viadutos, pontes, entre outros);

- Bairro;

- Região político administrativa, caso aplicável;

- Número de identificação do ponto luminoso de iluminação pública;

- Número do barramento ou identificação do poste, quer seja exclusivo de iluminação pública quer seja pertencente à distribuidora de energia elétrica local;

- Registro fotográfico;

- Coordenadas georreferenciadas (latitude e longitude);

- Tipo de consumo (medido ou por estimativa);

- $\mathrm{N}^{\circ}$ do medidor de referência;

- Características do Poste (altura, resistência e material componente);

- Características do(s) braço(s) ou suporte(s) que sustentam as luminárias de iluminação pública (altura de instalação, tamanho, material componente e angulação);

- Tipo e quantidade da luminária(s); 


\section{Revista Científica ANAP Brasil}

\section{ISSN 1984-3240 - Volume 14, número 32, 2020}

- Lâmpada(s) (tipo, quantidade e potência);

- Características dos reatores (externo, interno/integrado);

- Perdas dos reatores;

- Tipo de acionamento (em grupo ou individual);

- Data de instalação dos componentes (lâmpadas, relés e reatores);

- Data de coleta das informações;

- Horário de coleta das informações;

- Nome dos integrantes da equipe técnica que coletou as informações.

\subsection{Banco de dados geográficos e plataforma SIG}

Após término da coleta e cadastramento de todas as informações acima citadas, tem-se a real identidade da iluminação pública do município. Este banco de dados geográficos poderá inicialmente ser utilizado para elaboração de um inventário de quantidades e tipos de todos os ativos municipais de IP. Num segundo momento, poderá ser utilizado conjuntamente com auxílio de um software ou plataforma SIG para que o gestor público possa conhecer todo o sistema de iluminação existente e de sua responsabilidade. A figura 1 mostra o mapa de distribuição de pontos de iluminação pública da cidade do Recife.

Figura 1- Mapa de distribuição de pontos de iluminação pública da cidade do Recife

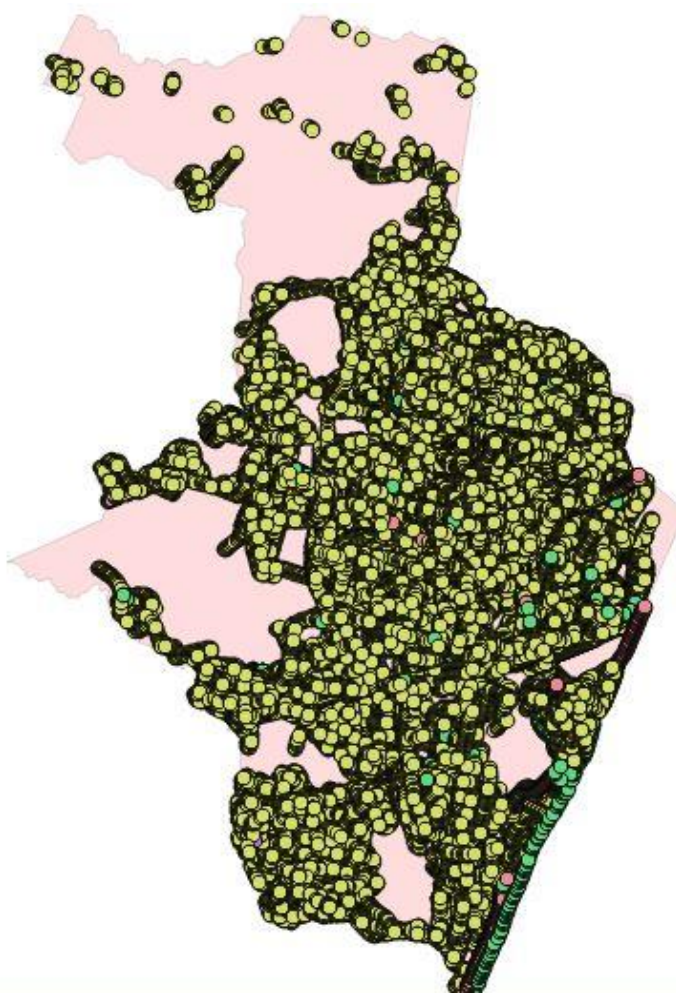

Fonte: AUTORES, 2018. 


\section{RESULTADOS E DISCUSSÃO}

\subsection{Faturamento do consumo}

Quanto ao tipo de conexão dos equipamentos de iluminação pública com a rede de distribuição de energia elétrica, os pontos luminosos podem ser classificados quanto ao tipo consumo, podendo ser do tipo medido ou estimado (por estimativa). Quando existirem medidores de energia elétrica e uma conta contrato que formalize a relação de fornecimento-consumo entre a distribuidora e o município, os pontos luminosos de iluminação pública conectados neste circuito são classificados como medidos. Para os equipamentos de iluminação pública conectados diretamente à rede de distribuição sem que haja um medidor específico para aferir o consumo desta carga, chamase esta condição de faturamento do tipo estimado.

De acordo com a seção X, art. 24 da resolução normativa da Agência Nacional de Energia Elétrica (ANEEL) N414/2010, para fins de faturamento da energia elétrica destinada à iluminação pública ou à iluminação de vias internas de condomínios, o tempo a ser considerado para consumo diário deve ser de 11 (onze) horas e 52 (cinquenta e dois) minutos. É ressalvado o caso de logradouros que necessitem de iluminação permanente, em que o tempo é de 24 (vinte e quatro) horas por dia do período de fornecimento. Este tempo será associado à carga definida pela potência das lâmpadas mais as perdas dos reatores e/ou equipamentos auxiliares, sendo gerada uma fatura por estimativa dos demais pontos luminosos de IP municipal.

Alguns problemas recorrentes da emissão desta fatura por estimativa por parte da distribuidora são causados pela desatualização do banco de dados existente. Dessa forma, nota-se a cobrança indevida por parte da distribuidora de pontos pertencentes a outros municípios (devido à falta de um completo conhecimento a respeito dos limites geográficos dos municípios) e pontos com características distintas da padronização adotada por cada cidade. Portanto, o banco de dados geográficos devidamente atualizado (realizado pelo ente municipal), quando associado a uma plataforma SIG é capaz de determinar e emitir uma memória de cálculo de consumo de energia elétrica a respeito do consumo estimado do município. Tal fato garante uma maior segurança ao gestor público, tanto na liquidação desta despesa, quanto ao uso adequado dos recursos públicos destinados a este fim.

Na figura 2 é mostrada a dispersão de pontos de IP fora da área da cidade do Recife. A área destacada em vermelho representa a área de Recife segundo dados atualizados do IBGE, enquanto a área em branco representa a cidade de Jaboatão dos Guararapes. Nota-se a existência de um grande aglomerado de pontos luminosos que geograficamente estão fora do município do Recife e, portanto, podem ser facilmente excluídos do banco de dados geográficos para posteriormente ser realizada a emissão de fatura de consumo. 


\title{
Revista Científica ANAP Brasil
}

\author{
ISSN 1984-3240 - Volume 14, número 32, 2020
}

Figura 2-Mapa de dispersão de pontos de iluminação pública fora da área da cidade do Recife

Fonte: AUTORES, 2018.

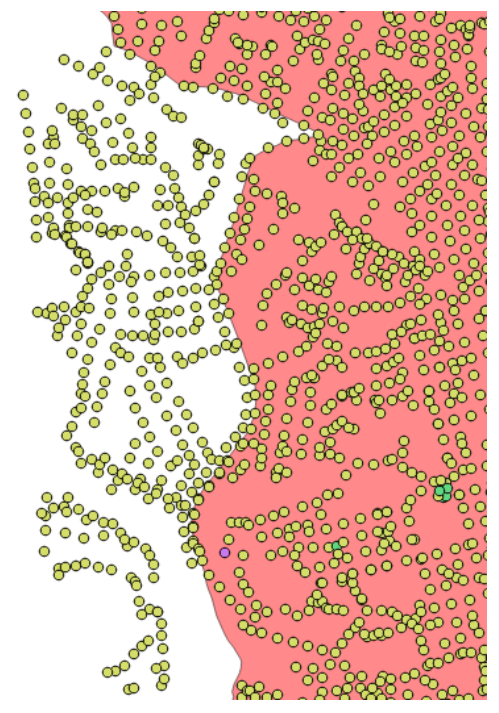

A figura 3 representa a coleta de pontos de iluminação no interior de áreas privadas do município. As áreas destacadas em vermelho representam as áreas privadas, existindo um grande aglomerado de pontos luminosos que geograficamente estão dentro destas áreas, portanto não havendo relação de consumo com o ente público e sim com o ente privado. Tais pontos luminosos também são facilmente excluídos após análise SIG.

A aplicação real da estratégia citada foi utilizada no sistema de iluminação pública da cidade do Recife no ano de 2017, tendo sido retirados do faturamento pontos em que o município não reconhecia a propriedade (lâmpadas mistas, vapor de mercúrio, incandescentes, halógenas, entre outras tecnologias). Foram retirados também pontos georreferenciados pertencentes a outros municípios e localizados no interior de propriedades privadas. Além disso destaca-se a atualização do cadastro a partir do Programa de Eficientização RELUZ, responsável pela substituição de aproximadamente 55.000 pontos luminosos. Abaixo (figura 4) se apresenta a redução do consumo de energia elétrica, por parte dos equipamentos de iluminação pública, de aproximadamente 1.5 MWh/mês na cidade de Recife desde o ano de 2012: 
Figura 4-Cadastro x Consumo (MWh/mês)

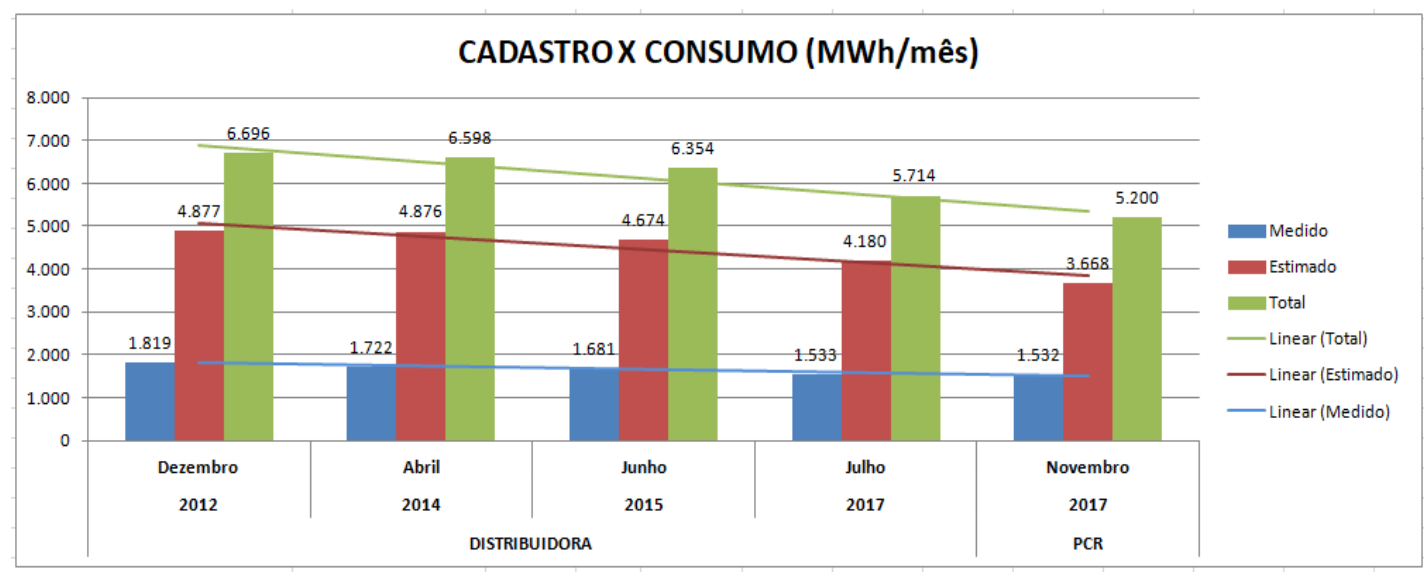

Fonte: AUTORES, 2018.

\subsection{Otimização de contratos, serviços de manutenção e implantação de sistema de gestão da iluminação pública}

A partir da identidade do sistema de iluminação pública definida após a coleta dos dados técnicos dos ativos, o gestor público tem o dever de otimizar o uso dos recursos públicos fazendo alterações contratuais necessárias e em casos extremos licitando novos contratos de manutenção. Os quantitativos de equipamentos existentes, seu estado atual quanto à vida útil e depreciação, seus tipos e suas condições de instalação são parâmetros extremamente necessários para o dimensionamento adequado dos insumos e mão-de-obra para manter em perfeito funcionamento a provisão do serviço essencial de iluminação pública à população de uma cidade.

O banco de dados geográficos cadastrado quando associado a uma plataforma de WebGIS também favorece o atendimento de demandas de manutenção num prazo mais curto. Sistemas e softwares que utilizam tecnologia GPS podem ser utilizados para traçar melhores rotas entre as equipes de manutenção e os pontos luminosos defeituosos facilmente localizados no mapa a partir de suas coordenadas georreferenciadas.

Além dos benefícios anteriormente citados, essa base de dados geográficos atualizada é capaz de condicionar a implantação de um sistema de gestão da iluminação pública, ferramenta que auxiliará o gestor público não só no atendimento das demandas de manutenção corretiva, mas também nas demandas de manutenção preventiva. Parte-se da observação da estimativa da vida útil declarada de cada equipamento (quando do seu cadastramento e coleta dos dados e da realização de novas manutenções, para um cadastro contínuo) facilitando a ocorrência de intervenções programadas sem que obrigatoriamente seja necessário que haja falha ou defeito do equipamento.

Estes aspectos de automatização e otimização na execução dos serviços de manutenção fazem com que o gestor público garanta uma maior segurança e confiabilidade do sistema por ele gerenciado, bem como amplo conhecimento de toda a cadeia de operações e intervenções que se sucedem em todo momento no sistema de iluminação pública de uma cidade. 


\title{
Revista Científica ANAP Brasil
}

\author{
ISSN 1984-3240 - Volume 14, número 32, 2020
}

utilizadas, quem as detém e a propriedade dos dados do sistema. Estas definições irão determinar o sucesso da implantação do sistema e sua continuidade ao longo do tempo. (ROSITO, 2009).

A aplicação real desta estratégia foi utilizada no sistema de iluminação pública da cidade do Recife no ano de 2018, onde houve a nova licitação dos contratos de manutenção da iluminação pública convencional da cidade. A expectativa é de que somente com estes ajustes e redimensionamentos de insumos e mão-de-obra, haja uma redução de despesas de manutenção de aproximadamente 1,2 milhões nos próximos 02 anos.

\subsection{Elaboração de novos projetos de iluminação pública}

O termo "Kernel" faz referência a um método estatístico de estimação de curvas de densidades. Neste método cada uma das observações é ponderada pela distância em relação a um valor central, o núcleo. De forma simples, o Mapa de Kernel é uma alternativa para análise geográfica do comportamento de padrões. No mapa é plotado, por meio métodos de interpolação, a intensidade pontual de determinado fenômeno em toda a região de estudo. Assim, tem-se uma visão geral da intensidade do processo em todas as regiões do mapa. A figura 5 mostra o mapa de Kernel da cidade do Recife.

Figura 5-- Mapa de Kernel de densidade de carga instalada dos pontos de IP da cidade do Recife

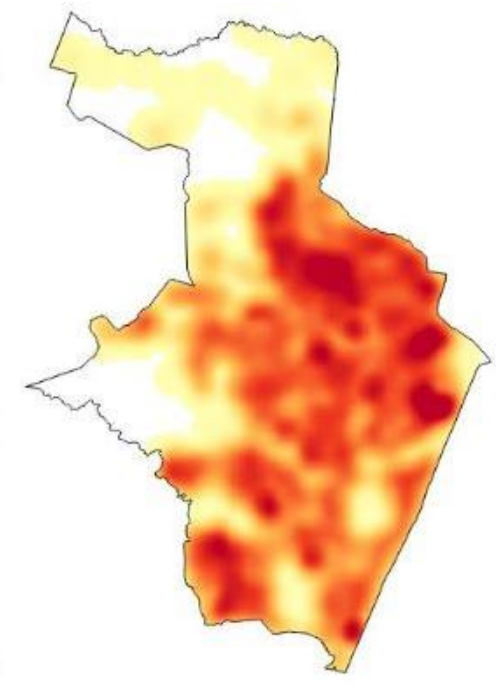

Fonte: SIMÕES (2018)

Pode-se destacar a concentração de carga dos pontos luminosos de iluminação pública dentro da área da cidade do Recife. As áreas mais escuras definem uma maior densidade de carga elétrica e as mais claras definem áreas com baixa concentração de carga. Este mapa auxilia o gestor público a facilmente identificar áreas em que há necessidade de uma eficientização dos equipamentos de iluminação pública, bem como áreas precárias de iluminação em que há necessidade de intervenção do ponto de vista de elaboração de novos projetos de expansão.

Além disso, o geoprocessamento do banco de dados geográficos em conjunto com plataformas SIG é capaz de informar a localização dos postes da distribuidora e dos postes exclusivos de iluminação pública, altura de instalação das luminárias, tipos de luminárias instaladas na cidade 


\title{
Revista Científica ANAP Brasil
}

\author{
ISSN 1984-3240 - Volume 14, número 32, 2020
}

com suas respectivas potências. Tais parâmetros são suficientes para a correta modelagem e elaboração de projetos luminotécnicos das vias da cidade, com auxílio de softwares de modelagem de iluminação.

O nível de iluminância média de uma via é um dos pontos chaves para elaboração de um bom projeto de iluminação. As intensidades emitidas pelas luminárias são controladas direcionalmente e distribuídas de acordo com a necessidade para visibilidade adequada (com rapidez, precisão e conforto). Outro fator a ser considerado na realização de um projeto de iluminação é a uniformidade, que é definido como a relação entre a iluminância mínima e a iluminância média. A qualidade da iluminação deve ser avaliada pela distribuição da luz no ambiente de forma mais natural e distribuída possível, evitando assim áreas escuras ao longo das vias. Os níveis de iluminância e uniformidade mínimos e obrigatórios estabelecidos na NBR 5101:2012 são definidos nas tabelas de 2 a 5 descritas abaixo:

Tabela 2- Classes de iluminação - tráfego de veículos

\begin{tabular}{lc}
\multicolumn{1}{c}{ Descrição da via } & $\begin{array}{c}\text { Classe de } \\
\text { lluminação }\end{array}$ \\
\hline Vias de trânsito rápido; Vias de alta velocidade de tráfego, com separação de pistas, sem & \\
cruzamentos em nível e com controle de acesso; Vias de trânsito rápido em geral; Auto- & \\
estradas. & V1 \\
Volume de tráfego intenso & V2 \\
Volume de tráfego médio & \\
\hline Vias arteriais; Vias de alta velocidade de tráfego com separação de pistas; Vias de mão & \\
dupla, com cruzamentos e travessias de pedestres eventuais em pontos bem definidos; & V1 \\
Vias rurais de mão dupla com separação por canteiro ou obstáculo. & V2 \\
Volume de tráfego intenso & \\
Volume de tráfego médio & V2 \\
\hline Vias coletoras; Vias de tráfego importante; Vias radiais e urbanas de interligação entre & V3 \\
bairros, com tráfego de pedestres elevado & V4 \\
Volume de tráfego intenso & \\
Volume de tráfego médio & V4 \\
Volume de tráfego leve & V5 \\
\hline Vias locais; Vias de conexão menos importante; Vias de acesso residencial & \\
Volume de tráfego médio & \\
\hline Volume de tráfego leve &
\end{tabular}




\section{Revista Científica ANAP Brasil}

\section{ISSN 1984-3240 - Volume 14, número 32, 2020}

Tabela 3-Níveis de iluminância e uniformidade - tráfego de veículos

\begin{tabular}{ccc}
\hline $\begin{array}{c}\text { Classe de } \\
\text { iluminação }\end{array}$ & $\begin{array}{c}\text { lluminância média mínima } \\
\text { lux }\end{array}$ & $\begin{array}{c}\text { Fator de uniformidade } \\
\text { mínimo } \\
U=E_{\text {min }} / E_{\text {med }}\end{array}$ \\
\hline V1 & 30 & 0,4 \\
\hline V2 & 20 & 0,3 \\
\hline V3 & 15 & 0,2 \\
\hline V4 & 10 & 0.2 \\
\hline V5 & 5 & 0,2
\end{tabular}

Fonte: NBR 5101:2012, iluminação pública - procedimento

Tabela 4-Classes de iluminação - tráfego de pedestres

\begin{tabular}{lc}
\hline \multicolumn{1}{c}{ Descrição da via } & Classe de lluminação \\
\hline $\begin{array}{l}\text { Vias de uso noturno intenso por pedestres (por exemplo, calçadões, passeios de zonas } \\
\text { comerciais) }\end{array}$ & P1 \\
\hline $\begin{array}{l}\text { Vias de grande tráfego noturno de pedestres (por exemplo, passeios de avenidas, praças, } \\
\text { áreas de lazer) }\end{array}$ & P2 \\
\hline Vias de uso noturno moderado por pedestres (por exemplo, passeios, acostamentos) & P3 \\
\hline Vias de pouco uso por pedestres (por exemplo, passeios de bairros residenciais) & P4 \\
\hline Fonte: NBR 5101:2012, iluminação pública - procedimento &
\end{tabular}

Tabela 5-Níveis de iluminância e uniformidade - tráfego de pedestres

\begin{tabular}{ccc}
\hline \multirow{2}{*}{ Classe de iluminação } & $\begin{array}{c}\text { Iluminância horizontal média } E_{\text {med }} \\
\text { lux }\end{array}$ & $\begin{array}{c}\text { Fator de uniformidade mínimo } \\
U=E_{\text {min }} / E_{\text {med }}\end{array}$ \\
\hline P1 & 20 & 0,3 \\
\hline P2 & 10 & 0,25 \\
\hline P3 & 5 & 0,2 \\
\hline P4 & 3 & 0,2 \\
\hline
\end{tabular}

Fonte: NBR 5101:2012, iluminação pública - procedimento

Portanto, os resultados obtidos a partir da modelagem da iluminação existente devem ser avaliados com base na NBR 5101:2012, iluminação pública - procedimento, onde não estando de acordo com os requisitos mínimos desta norma devem ser submetidos a um novo arranjo, a uma requalificação dos equipamentos ou remodelação a fim de que todos os requisitos técnicos normativos sejam atendidos. Foi utilizando desta metodologia que o projeto llumina Recife, promovido pela prefeitura da cidade do Recife, realizou a instalação de 5.045 novos pontos luminosos de iluminação pública em LED nos grandes corredores, periferias, praças e parques da cidade.

\section{CONCLUSÃO}

O geoprocessamento das informações obtidas a partir da aquisição de dados técnicos atualizados do sistema de iluminação pública permite ao gestor público que as manutenções corretivas a serem realizadas pelas equipes técnicas sejam mais eficientes, melhorando a qualidade e garantindo a continuidade do serviço prestado à população. Esta metodologia é apenas um artifício para que um bom gestor público e sua equipe técnica possam realizar um melhor planejamento nas 


\title{
Revista Científica ANAP Brasil
}

\author{
ISSN 1984-3240 - Volume 14, número 32, 2020
}

ações corretivas e implantação de ações preventivas no município.

É necessário também investir na capacitação destes gestores, pois eles devem dominar as ferramentas de gestão, geoprocessamento e geotecnologias citadas neste artigo para que possa utilizar o inventário, banco de dados do cadastro dos componentes de iluminação e sua atualização da melhor forma possível. Isso irá permitir um gerenciamento eficiente e integrado, possibilitando: o faturamento adequado do consumo de energia elétrica dos equipamentos de IP da cidade; a realização de estudos de otimização dos custos operacionais de manutenção; a elaboração de um plano diretor de iluminação pública; a implantação de um sistema de gerenciamento da iluminação pública, a adoção de técnicas de manutenção preventiva e preditiva e a elaboração de novos projetos de iluminação pública.

Diante do exposto, sabe-se que uma melhor qualidade na provisão do serviço de iluminação pública pode proporcionar uma melhor imagem da cidade, valorização do seu patrimônio histórico, melhora a sensação de conforto e segurança da população. Tem-se ainda o incentivo das atividades turísticas e comerciais na cidade, além de favorecer a utilização dos espaços públicos no período noturno.

\section{AGRADECIMENTOS}

Os autores agradecem à Prefeitura do Recife, especialmente à Autarquia de Manutenção e Limpeza Urbana (EMLURB) pelos dados fornecidos e suporte no desenvolvimento do trabalho. Agradecimentos também à Faculdade Estácio do Recife.

\section{REFERÊNCIAS}

ABNT, ASSOCIAÇÃO BRASILEIRA DE NORMAS TÉCNICAS. NBR 5101:2012 lluminação pública - procedimentos. Rio de Janeiro, 2012.

ALMEIDA, R. D.; PASSINI, E. Y. O espaço geográfico: Ensino e representação. 12 ed. São Paulo: Contexto, 2002.

ANEEL, Agência nacional de energia elétrica. Resolução Normativa ANEEL n. 414. Brasília, 2010.

ANEEL, Agência nacional de energia elétrica. Resolução Normativa ANEEL n. 479. Brasília, 2012.

BORGES, Karla Albuquerque de Vasconcelos. A Gestão Urbana e as Tecnologias de Informação e Comunicação. IP Informática Pública, Belo Horizonte, 2000.

BRASIL. Constituição (1988). Constituição da República Federativa do Brasil. Brasília, DF: Senado Federal: Centro Gráfico, 1988.

COSTA, Diogenes Cortijo. Diretrizes para Elaboração e Uso de Bases Cartográficas no Planejamento Municipal: Urbano, Rural e Transportes. São Paulo, 2001.

MARTINS, Juliana. O papel social da luz urbana. O setor elétrico, São Paulo, 2011.

MOREIRA, Vinícius de Araújo. Iluminação Elétrica. São Paulo: Edgard Blucher, 1999.

ROSITO, Luciano Haas. As origens da iluminação pública no Brasil, 2009. Disponível em HTTP://www.osetoreletrico.com.br. Acesso em 24 de Novembro de 2018.

SANTANA, S. A. Modelagem de comunicação em WebGis para a difusão de dados geográficos e promoção da análise espacial. Belo Horizonte, 2009.

XAVIER-DA-SILVA, Jorge. Geoprocessamento para a Análise Ambiental. 1. ed. Rio de Janeiro: D5 Produção Gráfica, 2001. Disponível em: http://www.lageop.ufrj.br/ 